\title{
Evaluation and comparison of nutritional quality and bioactive compounds of berry fruits from Lonicera caerulea, Ribes L. species and Rubus idaeus grown in Russia
}

\author{
Isabelle Lefèvre ${ }^{\mathrm{a}}$, Johanna Ziebel ${ }^{\mathrm{a}}$, Cédric Guignard ${ }^{\mathrm{a}}$, Artem Sorokin ${ }^{\mathrm{b}}$, Olga Tikhonova ${ }^{\mathrm{b}}$, \\ Natalia Dolganova $^{\mathrm{b}}$, Lucien Hoffmann ${ }^{\mathrm{a}}$, Pablo Eyzaguirre ${ }^{\mathrm{c}}$ and Jean-François Hausman ${ }^{\mathrm{a}, *}$ \\ ${ }^{a}$ Centre de Recherche Public - Gabriel Lippmann, Department Environment and Agro-biotechnologies, \\ Belvaux, Luxembourg \\ ${ }^{\mathrm{b}}$ N.I. Vavilov Research Institute of Plant Industry, St Petersburg, Russian Federation \\ ${ }^{\mathrm{c}}$ Bioversity International, Maccarese, Rome, Italy
}

Received 11 November 2010; accepted 21 February 2011

\begin{abstract}
The fruits of three berry species cultivated in Russia, Rubus idaeus, Ribes L. species (R. nigrum and $R$. nigrum $\times R$. dikuscha) and the less common Lonicera caerulea, were investigated for their minerals and phytochemical compounds. Under the same environmental conditions, differences in contents of nutrients and bioactive compounds among species were found. Lonicera caerulea contained the highest level of $\mathrm{K}$, Ribes $\mathrm{L}$. presented the highest content of $\mathrm{Ca}$, while $R$. idaeus displayed the highest content of $\mathrm{Mg}$ and different micro-elements (Fe, Mn, $\mathrm{Zn}$ and Mo). Lonicera caerulea and Ribes L. displayed the highest content of sugars, but the profile of individual sugars differed among each species, with a probable influence on the fruit's organoleptic quality. The most striking result was the polyphenolic contents of L. caerulea which was significantly higher than that of Ribes L. and $R$. idaeus, two species already known to contain large amounts of these antioxidant compounds. This difference was much higher when the subclass of anthocyanins is considered. These results revealed L. caerulea as a promising species from a nutritional perspective.
\end{abstract}

Keywords: Berry, blackcurrant, blue honeysuckle, carbohydrates, fruits, nutrients, phenolics, raspberry

\section{Introduction}

Berry fruits, consumed fresh or processed, are nutritionally valuable food, as they are rich sources of minerals, vitamins, sugars, dietary fibres, organic acids and polyphenolic compounds. They have gained attention because of their potential for improving human health. Their regular consumption was shown to exhibit numerous benefits such as cardioprotective effects, control of blood glucose levels by inhibiting starch digestive enzymes, or antimicrobial activities against human pathogens $[4,6,11,33,34]$. The different species of berries do not present the same

\footnotetext{
${ }^{*}$ Corresponding author: Jean-François Hausman, Centre de Recherche Public - Gabriel Lippmann, Department Environment and Agrobiotechnologies, 41 rue du Brill, L-4422 Belvaux, Luxembourg. Tel.: +352 470261 443; Fax: +352 47 02 64; E-mail: hausman@lippmann.lu.
} 
efficiency in the range of biological effects. Indeed, their efficiency is related to the quantitative and qualitative patterns in different active compounds [33,35]. Among the various phytochemicals, phenolics appear to largely contribute to the biological effects previously detailed $[6,26]$, the anthocyanin class being the most investigated. Due to both the quantitative and qualitative high diversity of these bioactive compounds, berry fruits are increasingly referred to as natural functional food. Albeit berry fruits are reported to contain valuable levels of mineral contents, studies related to their contents remain scarce, except for strawberry and fruit grape [17, 27]. Besides, the description of the glycemic properties of the berries is often left aside, the global sugar and organic acid contents being the sole indicators used [5].

Comparison of nutrients and antioxidant capacities of different fruits provides a valid tool to estimate their potential health benefits. Indeed, the bioactive content of berry fruit strongly varies among different species, but also among different genotypes within species [19, 24, 26, 38, 45]. Hence, some reviews described the composition of different berry fruit species and varieties $[14,15,19]$. In order to achieve these comparisons, berry samples are often purchased from different geographical areas and/or harvested in different years. However, numerous studies also showed that environmental and cultivation conditions affect nutrient and phytochemical composition [2, 16, 21, 44]. Moreover, characterization of different types of fruits for their content in nutrients and antioxidant compounds is often performed with different methodologies of extraction and quantification, which makes data comparison from different studies tricky $[22,32,42]$. Comparable analytical procedures for the evaluation of nutrient and phytochemical composition are compulsory to perform a comparison between berry species.

Furthermore, a majority of reports were carried out on the most common species (mainly strawberry and raspberry) while atypical ones may present similar, even higher, bioactive properties. In this respect, Lonicera caerulea, the blue honeysuckle, is an emerging crop which presents the advantage of growing under high latitudes and cold climates [18]. In these regions, it can represent the main berry at the disposal of the populations. Its fruit reaches ripeness early in the season. Some health benefits have already been assessed [41, 48], although only few studies concern its nutrient and phytochemical composition and diversity [10, 31, 40].

The N.I. Vavilov Institute of Plant Industry (VIR) holds and maintains collections of various berry crops: blackcurrant, redcurrant, gooseberry, raspberry, blackberry, strawberry, honeysuckle, hardy kiwi, magnolia vine and high-bush cranberry, with a total of more than 4700 accessions (http://www.vir.nw.ru). The aim of this study was to assess mean contents of nutritional and valuable compounds in different berry fruit species, raspberry (Rubus idaeus), blackcurrant (Ribes L. containing accessions from R. nigrum and R. nigrum $\times$ R. dikuscha) and the lesser known blue honeysuckle (Lonicera caerulea), based on a large number of accessions from the collections of the institute and cultivated under similar soil and climate conditions. The comparison of nutrient potential of berry fruits from raspberry, blackcurrant and blue honeysuckle accessions cultivated near St Petersburg, Russia, was achieved by applying to the whole set the same extraction and quantification protocols. Owing to the wide range of existing polyphenols and their pattern in berry fruits, total polyphenols and anthocyanins are considered in this study aiming at drawing up a comparison between the 3 considered species.

\section{Material and methods}

\subsection{Plant material and sample preparation}

Mature berries assessed by full colour development were harvested in 2007. Ninety-nine accessions of blackcurrants (Ribes nigrum L. and Ribes nigrum L. $\times$ Ribes dikuscha Fisch. Ex Turcz.), 48 accessions of raspberries (Rubus idaeus L.) and 25 accessions of blue honeysuckle (Lonicera caerulea L.) fruits were evaluated in this study. Fruits were collected from the Pavlovsk Research Station of the VIR $\left(59^{\circ} 39^{\prime} \mathrm{N}, 34^{\circ} 24^{\prime} \mathrm{E}, 69\right.$ masl) and immediately frozen under liquid nitrogen.

Berry fruits were roughly ground and freeze-dried at the VIR prior to their delivery to the Centre de Recherche Public - Gabriel Lippmann, Luxembourg. The material was then powder reduced with an automatic grinder (RM200, Retsch, Germany) and stored at $+4^{\circ} \mathrm{C}$ prior to extraction. For each accession, extraction was performed on three samples, which consisted each of pooled fruits from the same plant. Each sample was analysed in duplicate. 


\subsection{Mineral determination}

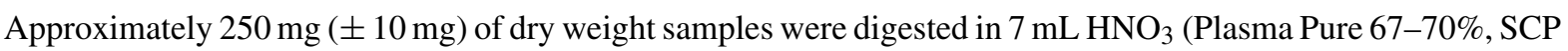
Science) (Courtaboeuf, France) and $3 \mathrm{~mL} \mathrm{H}_{2} \mathrm{O}_{2}$ (30\% in weight for trace metal analysis, Fisher Scientific) (Tournai, Belgium). Acid digestion was performed in Teflon tubes in a microwave oven (Anton Paar Multiwave 3000) (Graz, Austria) by increasing temperature and pressure until $200^{\circ} \mathrm{C}$ and 30 bars. At the end of the procedure, samples were diluted with $\mathrm{H}_{2} \mathrm{O}$ up to $25 \mathrm{~mL}$ and kept at $+4^{\circ} \mathrm{C}$ prior to analysis. Blank and certified reference material (white cabbage, IAEA-359, LGC Standards) (Molsheim, France) were included at each mineralization cycle for quality control. Samples were analysed by inductively coupled plasma mass spectrometry (ICP-MS) (Perkin Elmer Elan DRC-e) (Waltham, MA, USA).

\subsection{Carbohydrate extraction and measurement}

Water-soluble carbohydrate extraction was performed following the method described by Oufir et al. [30]. Briefly, about $80 \mathrm{mg}$ ( $\pm 5 \mathrm{mg}$ ) of freeze-dried material were ground in a $2 \mathrm{~mL}$ Eppendorf with a Retsch MM 200 automatic grinder (Retsch GmbH \& Co. KG, Haan, Germany) for $4 \mathrm{~min}$ at $22 \mathrm{~Hz}$ with two metallic beads pre-cooled in liquid nitrogen and extracted with $1 \mathrm{~mL}$ of an ethanol/water mixture (80/20; v/v) during $1 \mathrm{~h}$. The supernatant was collected and the residue left was extracted again with $0.5 \mathrm{~mL}$ of the same extraction solvant. The resulting supernatant was pooled to the first one and evaporated at reduced pressure in a SpeedVac concentrator (Heto, Thermo Electron Corporation, Waltham, MA). The extract was finally dissolved in $1 \mathrm{~mL}$ of water and filtered through a $0.45 \mu \mathrm{m}$ Acrodisc PVDF syringe filter prior to analysis using high-performance anion exchange chromatography coupled with pulsed amperometric detection (HPAEC-PAD) as previously described [30]. Analyses for carbohydrates were conducted on a Dionex HPLC ICS2500-BioLC (Sunnyvale, USA), with an AS-50 autosampler, a GS-50 gradient pump and an EG-50 eluent generator, with a PAD detection achieved with a gold working electrode and an $\mathrm{Ag} / \mathrm{AgCl}$ reference electrode (Dionex ED 40, Dionex Corp., USA). The analytical column was a Dionex CarboPac PA20 $(3 \mathrm{~mm} \times 150 \mathrm{~mm})$ in combination with CarboPac PA20 guard column $(3 \mathrm{~mm} \times 50 \mathrm{~mm}) \mathrm{kept}$ at $30^{\circ} \mathrm{C}$. Arabinose, xylose, melibiose, stachyose, raffinose, maltose, verbascose, cellobiose, and cellotriose contents in the fruit extracts were below the detection limit (data not shown).

\subsection{Polyphenol analysis}

\subsubsection{Extraction}

Approximately $80 \mathrm{mg}( \pm 5 \mathrm{mg})$ of powdered freeze-dried material was mixed with acetone/methanol/water/formic acid (40:40:20:0.1, v/v/v/v) according to Koca and Karadeniz [25]. After vortexing for $30 \mathrm{~s}$ and shaking for $30 \mathrm{~min}$ at $30^{\circ} \mathrm{C}$ with an Eppendorf Thermomixer Comfort (Eppendorf, Hamburg, Germany) at $1400 \mathrm{rpm}$, samples were centrifuged at $9000 \mathrm{~g}$, at $4^{\circ} \mathrm{C}$, during $10 \mathrm{~min}$. The supernatant was collected and stored below $4{ }^{\circ} \mathrm{C}$, and the residue left was extracted again with $0.5 \mathrm{~mL}$ of the same extraction solution. The resulting supernatant was pooled to the first one and evaporated at reduced pressure (Speedvac without heating). The final dried extract was re-suspended in $1 \mathrm{~mL}$ milli-Q water and filtered at $0.45 \mu \mathrm{m}$ (Acrodisc PVDF filters) prior to analysis.

\subsubsection{Total phenolic analysis}

Total phenolic content was measured using the Folin-Ciocalteu method [39] as described by André et al. [1]. Results were expressed as mg of gallic acid equivalents (GAE) per $100 \mathrm{~g}$ of DW from a gallic acid standard concentration curve.

\subsubsection{Total anthocyanin analysis}

Total anthocyanin content was determined with the $\mathrm{pH}$ differential method [12]. Absorbance was measured at 520 and $700 \mathrm{~nm}$ in $\mathrm{pH} 1.0$ and 4.5 buffers on the crude phenolic extract using a Beckman DU 800 spectrophotometer (Fullerton, CA). Results were expressed as mg of cyanidin 3-glucoside (cyanidin 3-O- $\beta$-glucopyranoside) equivalents per $100 \mathrm{~g}$ of DW from a cyanidin 3-glucoside (Polyphenols Laboratories AS, Sandnes, Norway) curve. 


\subsection{Statistical analysis}

The data were subjected to analysis of variance using JMP 8.0 (2008, SAS Institute Inc., Cary, NC). In order to assess normal distribution and equality of data, Q-Q plot and Levene's test were performed. When necessary, data were subjected to log-transformation to ensure homogeneity of variance. A multiple comparison procedure between means was performed with a Tukey test with a confidence limit of $95 \%$. Values presented in the text are means \pm SE.

\section{Results and discussion}

This study aimed at assessing mean contents of mineral and phytochemical in fruits of 3 berry species, each average encompassing data from a large number of accessions, all grown under similar soil and climate conditions.

\subsection{Mineral elements}

Average content of macro- and micro-mineral nutrients in berry fruits from each species are presented in Table 1. Pattern of mineral elements distribution significantly differed between species. Lonicera caerulea (blue honeysuckle) contained the highest level of $\mathrm{K}, R$. idaeus (raspberry) presented the highest content of $\mathrm{Mg}$, while Ribes L. (blackcurrant) displayed the highest content of $\mathrm{Ca}$. Ribes nigrum was already reported to contain higher levels of $\mathrm{K}$ and $\mathrm{Ca}$ than R. idaeus [17]. In the latest study, Ribes $\mathrm{L}$. was also reported to present higher contents of $\mathrm{Mg}$ than $R$. idaeus, but our results showed the inverse trend. Differences in accession type and number, as well as environmental conditions can explain these differences, as previously mentioned.

The fruits of $R$. idaeus contained the highest levels of 4 out of the 5 micro-nutrients analysed ( $\mathrm{Fe}, \mathrm{Mn}, \mathrm{Zn}$ and Mo). Lonicera caerulea fruits displayed the highest content of $\mathrm{Cu}$ of the 3 observed species. Selenium concentrations remained under the threshold of detection in the 3 species. Sodium concentrations remained under the threshold of detection in Ribes L. extracts and in a large number of samples in $L$. caerulea, and were then not analysed for the mean content in this species. Only Ribes L. displayed a detectable content of Na.

Since accessions from all species were cultivated under the same environmental conditions, the different mineral patterns clearly demonstrated differential capacity of the species to absorb ions from the soil and/or a specific capacity of redistribution within the overall plant [20]. Despite a growing interest in mineral supply from food [1, 13], only few studies underlined the variability of nutrient accumulation in different berry species.

Table 1

Average of mineral contents in fruits from Rubus idaeus, Lonicera caerulea and Ribes L. species expressed in mg or $\mu \mathrm{g}$ per $100 \mathrm{~g} \mathrm{DW}$

\begin{tabular}{lccc}
\hline & R. idaeus & L. caerulea & Ribes L. \\
\hline Macro-nutrients (mg per 100 g DW) & & & \\
$\mathrm{K}$ & $1251.7 \pm 18.2 \mathrm{a}$ & $1777.0 \pm 27.5 \mathrm{c}$ & $1293.6 \pm 11.7 \mathrm{~b}$ \\
$\mathrm{Mg}$ & $171.8 \pm 1.8 \mathrm{c}$ & $115.7 \pm 1.9 \mathrm{a}$ & $124.6 \pm 1.9 \mathrm{~b}$ \\
$\mathrm{Ca}$ & $242.6 \pm 3.4 \mathrm{a}$ & $266.0 \pm 6.7 \mathrm{~b}$ & $326.8 \pm 7.6 \mathrm{c}$ \\
$\mathrm{Na}$ & $\cdot$ &. & $1.5 \pm 0.0$ \\
$\mathrm{Micro}-$ nutrients $(\mu \mathrm{g}$ per $100 \mathrm{~g} \mathrm{DW})$ & & & \\
$\mathrm{Fe}$ & & & $3241.9 \pm 68.2 \mathrm{~b}$ \\
$\mathrm{Mn}$ & $4614.6 \pm 214.8 \mathrm{c}$ & $2909.7 \pm 48.8 \mathrm{a}$ & $1182.3 \pm 25.9 \mathrm{a}$ \\
$\mathrm{Zn}$ & $2652.4 \pm 151.6 \mathrm{c}$ & $1301.3 \pm 38.5 \mathrm{~b}$ & $1103.9 \pm 20.2 \mathrm{~b}$ \\
$\mathrm{Cu}$ & $1851.1 \pm 33.4 \mathrm{c}$ & $998.4 \pm 20.1 \mathrm{a}$ & $419.5 \pm 7.2 \mathrm{a}$ \\
$\mathrm{Mo}$ & $482.7 \pm 13.8 \mathrm{~b}$ & $688.6 \pm 20.3 \mathrm{c}$ & $17.9 \pm 1.5 \mathrm{a}$ \\
\hline
\end{tabular}

Note: Values are means \pm SE. Different letters indicate significant differences between species at the $\alpha=0.05$ level. 


\subsection{Sugars}

The content distribution of the 3 main carbohydrates in the studied berry genera is presented in Fig. 1. The results indicate that the tissue content of individual sugars differed significantly between species, as represented by the box plot which pooled $50 \%$ of the genus data in the box itself, the remainder being contained between the upper and lower edges. Few accessions presented extreme values. Glucose and fructose were found to be the
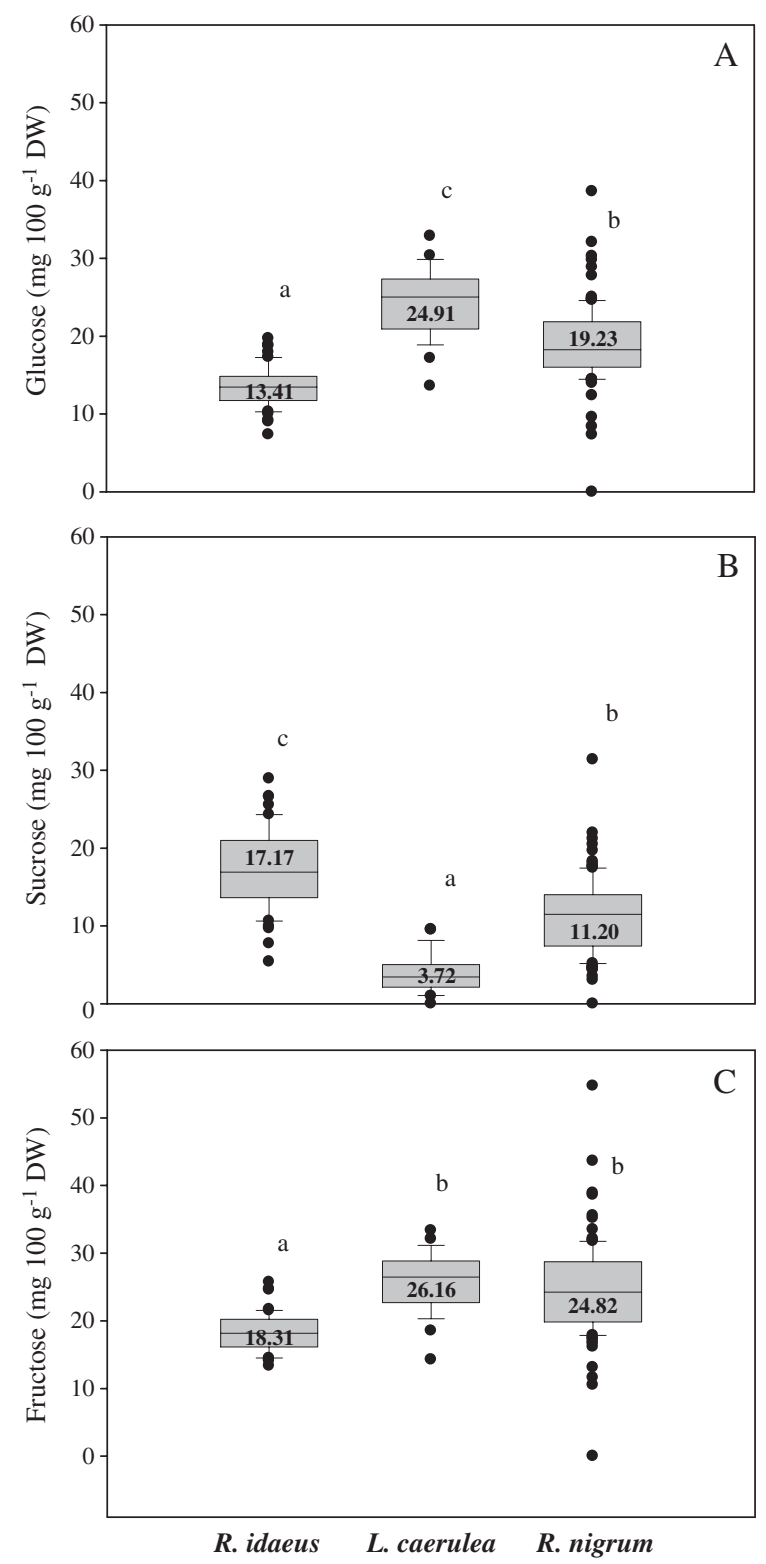

Fig. 1. Glucose (A), sucrose (B) and fructose (C) contents in fruits from Rubus idaeus, Lonicera caerulea and Ribes L. species. The upper and lower edges of the box indicate the 75 th and the 25 th percentile of the population data set, respectively. The median value of the data set is represented by the line in the box. The ends of the vertical lines indicate the 90 th and 10 th percentiles of the population data set. The points outside the ends of the vertical lines are extreme values. The average content corresponds to the value written in the box. Different letters indicate significant differences between species at the $\alpha=0.05$ level. $R$. idaeus, $n=48 ;$ L caerulea, $n=25 ;$ Ribes species, $n=99$. 
predominant sugars found in Ribes L. and L. caerulea, as already mentioned in literature for blackcurrant [36], with a concentration being 1.7 to 7 times that of sucrose. Indeed, L. caerulea presented very low disaccharide sucrose levels compared to Ribes L. and R. idaeus, but, on the contrary, it contained the highest glucose level. The 3 sugars were more equally distributed in $R$. idaeus, with a predominance of sucrose and fructose. Rubus idaeus contained lower levels of glucose and fructose than Ribes L., but presented the highest content of sucrose of the 3 studied species. Average content of the sum of the 3 main carbohydrates present in the studied berry fruits indicated

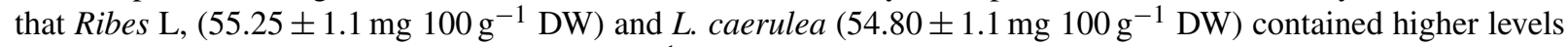

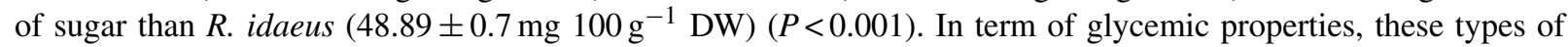
carbohydrates are easily assimilated and fully metabolized [3, 46]. Nevertheless, in terms of organoleptic qualities, sweetness, a desirable commercial characteristic, is greatly influenced by the total and relative amounts of sugars and organic acids. It may be quantified through the sweetness index [23], which is influenced by the total carbohydrate content as well as by the carbohydrate composition. The contribution of each carbohydrate may be calculated according to a factor assigned to each of them. Fructose and sucrose are considered 2.30 and 1.35 times sweeter than glucose, respectively. Due to their higher content in carbohydrates and more especially their high content in fructose, L. caerulea and Ribes L, presented a higher sweetness index (90.12 and 91.43, respectively) than $R$. idaeus (78.70).

\subsection{Polyphenolics}

Phenolic compounds are considered to be the most important group of compounds for antioxidant activity of fruits and vegetables [9]. Folin-Ciocalteu's method allows the estimation of all phenolic compounds present in the samples, including anthocyanins. Figure 2A reports the average value of the total polyphenols quantified for each species. Lonicera caerulea contained the highest content of total polyphenols with $5559.7 \mathrm{mg}$ GAE per $100 \mathrm{~g}$ DW. Despite a large variability within this species represented by the data distribution in the box plot, it significantly differed from Ribes L, which contained $3953.0 \mathrm{mg} \mathrm{GAE}$ per $100 \mathrm{~g}$ DW. It is interesting to notice some accessions with extreme high polyphenol values, especially in L. caerulea species. Rubus idaeus is the species with the lowest total polyphenol content with $3042.7 \mathrm{mg}$ GAE per $100 \mathrm{~g}$ DW. Ribes nigrum was already reported to contain a higher level of polyphenolic compounds than $R$. idaeus by some authors [7], while others described similar values [19].

Among the large polyphenolic group, anthocyanins are a class of over 500 compounds that provide the red, purple and blue colours of many vegetables and fruits. Interest in anthocyanins has recently increased since they have been reported to present strong antioxidant capacities [43]. Their average contents in fruits from the different species are presented in Fig. 2B. Lonicera caerulea contained high levels of those compounds, with an average content of $9429.4 \mathrm{mg} \mathrm{Cy}$-3-glc eq per $100 \mathrm{~g} \mathrm{DW}$, which is more than 2-times higher than those of Ribes L, even though the latter species presented high contents of total anthocyanins with $3943.3 \mathrm{mg}$ Cy-3-glc eq per $100 \mathrm{~g}$ DW. Rubus idaeus contained a largely lower content with $616.1 \mathrm{mg}$ Cy-3-glc eq per $100 \mathrm{~g}$ DW respect to the other species, despite the fact that the four yellow-coloured accessions were not taken into account in the calculation of the average of total anthocyanin level in this species. Previous studies already reported lower amounts of anthocyanins in $R$. idaeus compared to $R$. nigrum [19].

In France, fruit and vegetable intake is estimated to account for $28 \%$ of daily polyphenol intake, when this value is considered to be $1 \mathrm{~g}$ per day $[8,37]$. The daily intake of anthocyanins in the U.S. diet is estimated to be $12.5 \mathrm{mg} / \mathrm{day}$ [47]. Anthocyanins are mainly found in fresh berries, fruits, and some vegetables. According to Wu et al. [47], blackcurrant and raspberry contained in average $476 \mathrm{mg}$ and $92.1 \mathrm{mg}$ per $100 \mathrm{~g} \mathrm{FW}$, respectively. The amount of anthocyanins in blackcurrant is much higher than in vegetables reported to contain anthocyanins such as black bean (44.5 mg per $100 \mathrm{~g} \mathrm{FW}$ ), eggplant ( $85.7 \mathrm{mg}$ per $100 \mathrm{~g} \mathrm{FW}$ ), red leaf lettuce ( $2.2 \mathrm{mg}$ per $100 \mathrm{~g} \mathrm{FW}$ ), red onion ( $48.5 \mathrm{mg}$ per $100 \mathrm{~g} \mathrm{FW})$, red raddish (100.1 mg per $100 \mathrm{~g} \mathrm{FW}$ ) and small red bean $(6.7 \mathrm{mg}$ per $100 \mathrm{~g} \mathrm{FW})$. Among the studied vegetables, only red cabbage contained substantial values ( $322 \mathrm{mg}$ per $100 \mathrm{~g} \mathrm{FW}$ ). In humans, the bioavailability of dietary anthocyanins is reported to be low [29]. However, their beneficial effects are evident and few studies have concerned their metabolism after consumption and their derivate-compounds. 

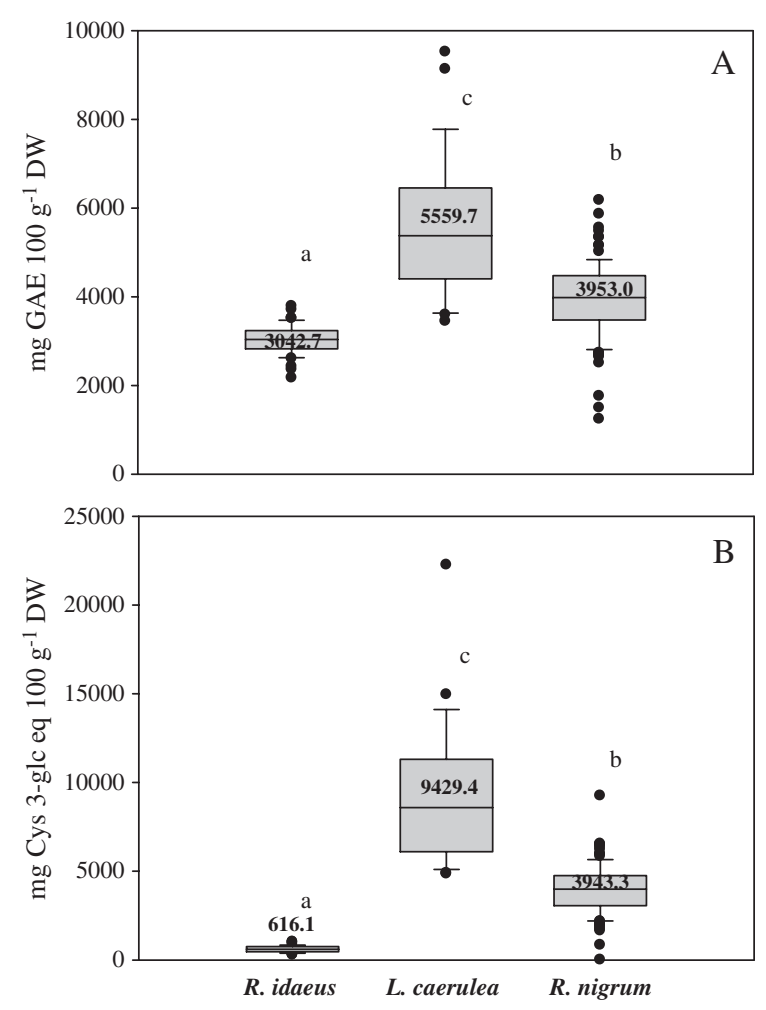

Fig. 2. Total polyphenol (A) and total anthocyanin (B) contents in fruits from Rubus idaeus, Lonicera caerulea and Ribes L. species. The upper and lower edges of the box indicate the 75 th and the 25 th percentile of the population data set, respectively. The median value of the data set is represented by the line in the box. The ends of the vertical lines indicate the 90 th and 10 th percentiles of the population data set. The points outside the ends of the vertical lines are extreme values. The average content corresponds to the value written in the box. Different letters indicate significant differences between species at the $\alpha=0.05$ level. $R$. idaeus, $n=48 ; L$. caerulea, $n=25 ;$ Ribes species, $n=99$. The four yellow accessions of $R$. idaeus with negligible anthocyanin content were not included in the box plot and average of anthocyanin content $(n=44)$.

\subsection{Conclusions}

The potential of raspberry as a rich source of bioactive compounds has begun to attract attention [28, 34, 42]. This study compares its content of bioactive compounds with another well known, even less studied berry species, the blackcurrant, and an emerging crop species, the poorly studied blue honeysuckle. Our data showed that the importance of these two last species in nutrient and phytochemical supply was relevant, even higher than that of raspberries for some nutrients or phytochemicals. This study emphasises the potential of blue honeysuckle, especially for its anthocyanin production. However, in humans the bioavailability of those dietary compounds is debated. Further studies are thus needed to appreciate the potential of the studied species in term of bioactivity.

\section{Acknowledgments}

The authors are grateful to N. Tikhonova and L. Solinhac for excellent technical assistance. This work was financially supported by the Ministry of Finance, Luxembourg. 


\section{References}

[1] C.M. André, M. Ghislain, P. Bertin, M. Oufir, M.D. Herrera, L. Hoffmann, J.F. Hausman, Y. Larondelle and D. Evers, Andean potato cultivars (Solanum tuberosum L.) as a source of antioxidant and mineral micronutrients, Journal of Agricultural and Food Chemistry 55 (2007), 366-378.

[2] M.J. Anttonen and R.O. Karjalainen, Environmental and genetic variation of phenolic compounds in red raspberry, Journal of Food Composition and Analysis 18 (2005), 759-769.

[3] N.G.L. Asp, Classification and methodology of food carbohydrates as related to nutritional effects, American Journal of Clinical Nutrition 61 (1995), S930-S937.

[4] I. Badjakov, M. Nikolova, R. Gevrenova, V. Kondakova, E. Todorovska and A. Atanassov, Bioactive compounds in small fruits and their influence on human health, Biotechnology \& Biotechnological Equipment 22 (2008), 581-587.

[5] C.E. Basson, J.H. Groenewald, J. Kossmann, C. Cronjé and R. Bauer, Sugar and acid-related quality attributes and enzyme activities in strawberry fruits: Invertase is the main sucrose hydrolysing enzyme, Food Chemistry 121 (2010), 1156-1162.

[6] M. Battino, J. Beekwilder, B. Denoyes-Rothan, M. Laimer, G.J. McDougall and B. Mezzetti, Bioactive compounds in berries relevant to human health, Nutrition Reviews 67 (2009), S145-S150.

[7] S. Benvenuti, F. Pellati, M. Melegari and D. Bertelli, Polyphenols, anthocyanins, ascorbic acid, and radical scavenging activity of Rubus, Ribes, and Aronia, Journal of Food Science 69 (2004), C164-C169.

[8] P. Brat, S. Georgé, A. Bellamy, L. Du Chaffaut, A. Scalbert, L. Mennen, N. Arnault and M.J. Amiot, Daily polyphenol intake in France from fruit and vegetables, Journal of Nutrition 136 (2006), 2368-2373.

[9] L. Bravo, Polyphenols: Chemistry, dietary sources, metabolism, and nutritional significance, Nutrition Reviews 56 (1998), $317-333$.

[10] V.I. Deineka, V.N. Sorokopudov, L.A. Deineka, E.I. Shaposhnik and S.V. Kol'tsov, Anthocyans from fruit of some plants of the Caprifoliaceae family, Chemistry of Natural Compounds 41 (2005), 162-164.

[11] I. Erlund, R. Koli, G. Alfthan, J. Marniemi, P. Puukka, P. Mustonen, P. Mattila and A. Jula, Favorable effects of berry consumption on platelet function, blood pressure, and HDL cholesterol, American Journal of Clinical Nutrition 87 (2008), 323-331.

[12] M.M. Giusti and R.E. Wrolstad, Anthocyanins. Characterization and measurement of anthocyanins by UV-visible spectroscopy, in: Current Protocols in Food Analytical Chemistry, R.E. Wrolstad, ed., Wiley, New York, 2001, pp. F.2.1-F.2.13

[13] M.A. Grusak and D. DellaPenna, Improving the nutrient composition of plants to enhance human nutrition and health, Annual Review of Plant Physiology and Plant Molecular Biology 50 (1999), 133-161.

[14] S. Häkkinen, M. Heinonen, S. Karenlampi, H. Mykkanen, J. Ruuskanen and R. Torronen, Screening of selected flavonoids and phenolic acids in 19 berries, Food Research International 32 (1999), 345-353.

[15] S.H. Häkkinen, S.O. Karenlampi, I.M. Heinonen, H.M. Mykkanen and A.R. Torronen, Content of the flavonols quercetin, myricetin, and kaempferol in 25 edible berries, Journal of Agricultural and Food Chemistry 47 (1999), 2274-2279.

[16] J.C. Hargreaves, M.S. Adl, P.R. Warman and H.P.V. Rupasinghe, The effects of organic and conventional nutrient amendments on strawberry cultivation: Fruit yield and quality, Journal of the Science of Food and Agriculture 88 (2008), 2669-2675.

[17] A. Hegedús, E. Balogh, R. Engel, B.Z. Sipos, J. Papp, A. Blázovics and E. Stefanovits-Bányai, Comparative nutrient element and antioxidant characterization of berry fruit species and cultivars grown in Hungary, Hortscience $\mathbf{4 3}$ (2008), 1711-1715.

[18] K.E. Hummer, Blue honeysuckle: A new berry crop for North America, Journal of the American Pomological Society 60 (2006), 3-8.

[19] M.P. Kähkönen, A.I. Hopia and M. Heinonen, Berry phenolics and their antioxidant activity, Journal of Agricultural and Food Chemistry 49 (2001), 4076-4082.

[20] A.J. Karley and P.J. White, Moving cationic minerals to edible tissues: potassium, magnesium, calcium, Current Opinion in Plant Biology 12 (2009), 291-298.

[21] A. Kassim, J. Poette, A. Paterson, D. Zait, S. McCallum, M. Woodhead, K. Smith, C. Hackett and J. Graham, Environmental and seasonal influences on red raspberry anthocyanin antioxidant contents and identification of quantitative traits loci (QTL), Molecular Nutrition \& Food Research 53 (2009), 625-634.

[22] P. Kerchev and S. Ivanov, Influence of extraction techniques and solvents on the antioxidant capacity of plant material, Biotechnology \& Biotechnological Equipment 22 (2008), 556-559.

[23] A. Keutgen and E. Pawelzik, Modifications of taste-relevant compounds in strawberry fruit under NaCl salinity, Food Chemistry 105 (2007), 1487-1494.

[24] S. Khanizadeh, D. Rekika, B. Ehsani-Moghaddam, R. Tsao, R. Yang, M.T. Charles, J.A. Sullivan, L. Gauthier, A. Gosselin, A.M. Potel, G. Reynaud and E. Thomas, Horticultural characteristics and chemical composition of advanced raspberry lines from Quebec and Ontario, Lwt-Food Science and Technology 42 (2009), 893-898.

[25] I. Koca and B. Karadeniz, Antioxidant properties of blackberry and blueberry fruits grown in the Black Sea Region of Turkey, Scientia Horticulturae 121 (2009), 447-450.

[26] V. Kondakova, I. Tsvetkov, R. Batchvarova, I. Badjakov, T. Dzhambazova and S. Slavov, Phenol compounds - qualitative index in small fruits, Biotechnology \& Biotechnological Equipment 23 (2009), 1444-1448.

[27] C.G. Kowalenko, Accumulation and distribution of micronutrients in Willamette red raspberry plants, Canadian Journal of Plant Science 85 (2005), 179-191. 
[28] M. Liu, X.Q. Li, C. Weber, C.Y. Lee, J. Brown and R.H. Liu, Antioxidant and antiproliferative activities of raspberries, Journal of Agricultural and Food Chemistry 50 (2002), 2926-2930.

[29] T.K. McGhie and M.C. Walton, The bioavailability and absorption of anthocyanins: Towards a better understanding, Molecular Nutrition \& Food Research 51 (2007), 702-713.

[30] M. Oufir, S. Legay, N. Nicot, K. Van Moer, L. Hoffmann, J. Renaut, J.F. Hausman and D. Evers, Gene expression in potato during cold exposure: Changes in carbohydrate and polyamine metabolisms, Plant Science 175 (2008), 839-852.

[31] I. Paliková, J. Heinrich, P. Bednář, P. Marhol, V. Křen, L. Cvak, K. Valentová, F. Růžička, V. Holá, M. Kolář, V. Šimánek and J. Ulrichová, Constituents and antimicrobial properties of blue honeysuckle: a novel source for phenolic antioxidants, Journal of Agricultural and Food Chemistry 56 (2008), 11883-11889.

[32] B. Pliszka, G. Huszcza-Ciołkowska and E. Wierzbicka, Effects of extraction conditions on the content of anthocyanins and bioelements in berry fruit extracts, Communications in Soil Science and Plant Analysis 39 (2008), 753-762.

[33] R. Puupponen-Pimiä, L. Nohynek, H.L. Alakomi and K.M. Oksman-Caldentey, Bioactive berry compounds - novel tools against human pathogens, Applied Microbiology and Biotechnology 67 (2005), 8-18.

[34] A.V. Rao and D.M. Snyder, Raspberries and human health: a review, Journal of Agricultural and Food Chemistry 58 (2010), $3871-3883$.

[35] H.A. Ross, G.J. McDougall and D. Stewart, Antiproliferative activity is predominantly associated with ellagitannins in raspberry extracts, Phytochemistry 68 (2007), 218-228.

[36] M. Sandell, O. Laaksonen, R. Järvinen, N. Rostiala, T. Pohjanheimo, K. Tiitinen and H. Kallio, Orosensory profiles and chemical composition of black currant (Ribes nigrum) juice and fractions of press residue, Journal of Agricultural and Food Chemistry 57 (2009), 3718-3728.

[37] A. Scalbert and G. Williamson, Dietary intake and bioavailability of polyphenols, Journal of Nutrition 130 (2000), 2073S-2085S.

[38] J. Scalzo, A. Politi, N. Pellegrini, B. Mezzetti and M. Battino, Plant genotype affects total antioxidant capacity and phenolic contents in fruit, Nutrition 21 (2005), 207-213.

[39] V.L. Singleton and J.A. Rossi, Colorimetry of total phenolics with phosphomolybdic-phosphotungstic acid reagents, American Journal of Enology and Viticulture 16 (1965), 144-158.

[40] I. Svarcova, J. Heinrich and K. Valentova, Berry fruits as a source of biologically active compounds: the case of Lonicera caerulea, Biomedical Papers 151 (2007), 163-174.

[41] A. Svobodová, A. Zdařilová and J. Vostálová, Lonicera caerulea and Vaccinium myrtillus fruit polyphenols protect HaCaT keratinocytes against UVB-induced phototoxic stress and DNA damage, Journal of Dermatological Science 56 (2009), 196-204.

[42] M. Tosun, S. Ercisli, H. Karlidag and M. Sengul, Characterization of red raspberry (Rubus idaeus L.) genotypes for their physicochemical properties, Journal of Food Science 74 (2009), C575-C579.

[43] H. Wang, G.H. Cao and R.L. Prior, Oxygen radical absorbing capacity of anthocyanins, Journal of Agricultural and Food Chemistry 45 (1997), 304-309.

[44] S.Y. Wang, C.T. Chen and C.Y. Wang, The influence of light and maturity on fruit quality and flavonoid content of red raspberries, Food Chemistry 112 (2009), 676-684.

[45] S.Y. Wang and H.S. Lin, Antioxidant activity in fruits and leaves of blackberry, raspberry, and strawberry varies with cultivar and developmental stage, Journal of Agricultural and Food Chemistry 48 (2000), 140-146.

[46] M.L. Wheeler and F.X. Pi-Sunyer, Carbohydrate issues: Type and amount, Journal of the American Dietetic Association 108 (2008), S34-S39.

[47] X.L. Wu, G.R. Beecher, J.M. Holden, D.B. Haytowitz, S.E. Gebhardt and R.L. Prior, Concentrations of anthocyanins in common foods in the United States and estimation of normal consumption, Journal of Agricultural and Food Chemistry 54 (2006), 4069-4075.

[48] A. Zdařilová, A.R. Svobodová, K. Chytilová, V. Šimánek and J. Ulrichová, Polyphenolic fraction of Lonicera caerulea L. fruits reduces oxidative stress and inflammatory markers induced by lipopolysaccharide in gingival fibroblasts, Food and Chemical Toxicology 48 (2010), $1555-1561$. 